\title{
The Impact of Networking on
}

\section{Library Management}

\begin{abstract}
The provision of library services through networks will impact the way libraries are managed. Changes in collection development, cataloging, interlibrary loan, reference work, and document delivery are cited as activities already affected. Several specific management problems, including resource reallocation, personnel, and resource imbalance, are discussed. It is concluded that library managers would be well advised to review how networks might impact their operations so that appropriate solutions can be formulated as soon as possible.
\end{abstract}

A

S SOCIETY'S PROBLEMS become more complex, decision makers will become more dependent upon the availability of accurate information in order to solve problems. The recognition of this dependency has caused some governmental decision makers as well as information professionals to seek ways in which to overhaul the nation's informationhandling systems. Many of the contemporary issues were addressed in the recent report issued by the National Commission on Libraries and Information Science (NCLIS). In it the commission recommended the development of a national network that would increase bibliographical and physical access to library materials to all citizens. ${ }^{1}$

While NCLIS may set the tone for future planning and developmental activities, in fact, many libraries are already deeply involved with networking. Recently, Susan Martin, in her state-of-the-art report on network development, listed those organizations that could be defined as networks. The list reflects the impressive progress that has been made in various parts of the country. ${ }^{2}$

In March 1977 the Librarian of Congress announced the formation of a committee consisting of representatives of organizations now engaged in network development to advise the librarian of short- and long-range

Richard M. Dougherty is university librarian, University of California, Berkeley. programs related to (1) the definition of objectives and functions of the national library and information service network; (2) the components of the network; (3) the roles of the components, including the Library of Congress; and (4) technical bibliographic policy considerations and tasks to be performed for building of the network. Although many years will pass before the lofty goals set forth in the commission's report are achieved, nonetheless, the first steps have been taken.

Networks will deliver bibliographic information to libraries in a variety of formats. Up to now these data have been used primarily to support local cataloging operations. Location data are also being added to the bibliographic data bases so that these de facto union catalogs will gradually become valuable finding tools.

But cataloging data are not the only form of bibliographic information that libraries are utilizing. Computerized information services that supply bibliographic citations, supplemented by key words and/or abstracts (e.g., System Development Corporation, Lockheed Corporation, and the New York Times), are becoming regular components of library reference operations. These systems represent only the first generation; research and development engineers are already predicting that new technologies will make it economically viable for systems to store 
not only citations and abstracts but to accommodate as well entire texts in the not too distant future.

Although this paper is focused on managerial implications, the availability of computer-produced products has already generated a plethora of practical and philosophical issues. Should libraries charge for these new services? If so, who should be charged? How much? Should certain groups be partially or totally subsidized? There is every reason to believe that today's generation of computer-based services is only the harbinger of greater changes to come.

Most library managers need not be as concerned about the actual structure of the network as they must be about the products it delivers or the impact these products will have on library policies, activities, and services. Experience to date suggests that significant changes are in the offing. Fortunately, enough is known about what is likely to occur to enable managers to prepare for future eventualities.

The purpose of this paper is to heighten awareness of several significant trends. The paper examines five areas in which change is already evident and describes some of the problems associated with these changes.

\section{AREAS OF CHANGE}

\section{Collection Development}

The ability of libraries to share on-order information will facilitate coordinated, interinstitutional collection development. For the first time, book selectors on one campus will have immediate access to the selection decisions of colleagues who are responsible for book selection in comparable subjects or languages at other institutions.

It may become easier to persuade users, who now insist that all books and journals must be located near at hand on campus, that libraries can share resources with neighboring institutions without degrading the quality of campus educational programs. This realization could pave the way for other decisions that could change thinking about book collections, their size and housing. For example, off-campus shelving facilities might become a more acceptable alternative to house selected categories of materials now shelved in campus library facilities.

\section{Cataloging}

The library community is already aware of the dramatic impact the Ohio College Library Center (OCLC) has had on traditional cataloging procedures. OCLC's growth has been phenomenal; it now serves the daily needs of more than 1,000 libraries. It is already clear that the staffing patterns of the typical catalog department of 1978 are quite different from departments of the $1950 \mathrm{~s}$ and 1960 s.

One particularly significant side benefit of the enormous OCLC data base has been its use to aid libraries to eliminate longstanding backlogs of uncataloged materials. Recently the University of California at San Diego began to utilize OCLC's data base with the expressed purpose of reducing its 300,000 -volume arrearage of uncataloged materials.

\section{Interlibrary Loan}

Quicker access to bibliographic data through networks will produce a gradual shift in the traditional interlibrary lending patterns among institutions. Those who desire materials will be able to discover more easily which libraries own a particular title; they will also be able to address a request to the nearest library, instead of the present tendency of routing automatically a request to the nearest large research library. The long-term effect should be to lighten the lending burden shouldered by the research libraries. Other libraries, however, may be required to increase the budgets of their interlibrary loan units to accommodate increased work loads.

\section{Reference Work}

The advent of computerized information data bases has already added an exciting new dimension to library information services. These data bases have already demonstrated their worth as effective, convenient tools to researchers. Many libraries now provide these services on a regular basis. But a corollary development has been the discovery of how much work is involved in training staff to write profiles, the extra work loads caused by the need for staff to provide instruction to library users, and the operational complexities of interfacing with the system. 


\section{Document Delivery}

Today very few academic libraries provide document delivery service to their clienteles. As the profession improves its accessibility to machine-readable bibliographic data bases, demands will be generated for improved document delivery systems.

\section{Prospective Problems}

As more library activities are impacted by network services, a chain of events will be set into motion that will create a new generation of problems for library managers. It will become increasingly apparent that there are imbalances in the distribution of dollars among library activities. As functions such as cataloging and acquisitions are changed, reduced, or phased out, it will be necessary to retrain staff to perform new functions. The improved accessibility to bibliographic availability will burden further the antiquated and inefficient document delivery systems.

Although these problems-(1) resource reallocation, (2) personnel problems, and (3) resource imbalances-are only three of the many problems that will confront tomorrow's library manager, all are central and merit careful examination.

\section{Resource Reallocation}

Resource reallocation is one of the most talked about but least understood of today's current managerial problems. The term, "reallocation," is used to designate a change in the distribution pattern of funds among a group of activities. The concept is not difficult to grasp, but the factors that must be taken into consideration can be complex, often subtle. A plan to reallocate resources requires careful planning and preparation. Librarians seem to be aware of the need to reallocate, but as yet there seems to be little evidence in the literature that formal plans for reallocation are commonplace.

It is relatively easy to illustrate how complex this process can be. For example, a library decides to subscribe to the services of OCLC; consequently, it no longer requires the same number of staff to perform some functions related to cataloging. As funds are generated through savings in labor costs, some of the savings may have to be used to defray the monthly OCLC computer bill. At the same time, staff who have been released from their former duties may have to be retrained and provisions made to incorporate them into different library units. This reallocation process is likely to impact the library's future budget requests, not only for the units directly affected by OCLC, but also public service units, particularly if the library has transferred staff from technical services to public services.

Libraries that introduce automated services, unless totally supported by special budgetary augmentations, will have to fund the automated activities from existing budgeted funds. Most libraries will defray these costs by reallocating funds from existing personnel budgets into computer support budgets. But as the utilization of computer-based network services grows, library managers may have to readjust fund distribution patterns in order to meet shifting service, organizational, and operational needs.

Fund reallocations may be particularly difficult for libraries that are bound by the provisions of existing labor agreements or by state fiscal regulations. Since so few libraries operate under rigid collective bargaining agreements, this should not prove too troublesome; but overly restrictive fiscal regulations present a much more formidable challenge, as many state universities and colleges are prohibited from taking actions that private industry would view as sound, prudent management practices.

Many traditional restrictions were established to increase budgetary control, but, as is generally recognized, such restrictive fiscal policies tend to contribute to the wastage so common with public agency funds. In the near future, pressures to reallocate existing resources in order to integrate new technologies may encourage, hopefully, state agency officials to grant greater budget flexibility. There is need to educate and persuade officials of funding agencies that greater budgetary discretion would contribute to greater operational effectiveness.

\section{Personnel Problems}

The most sensitive issues facing library managers will continue to be those related to personnel. Confrontations seem unavoidable since technological developments will 
probably displace some library staff. These positions will represent jobs that no longer need to be performed manually, and the funds released will be needed to pay for the new technologies.

Ironically, more not fewer librarians will be needed if the profession is to take full advantage of the new tools made available through technological advances. For example, more reference librarians will be required to instruct and/or mediate computer-based reference systems for users.

Fortunately, a sizable proportion of the cutbacks can be accomplished through the process of natural attrition, but in some libraries, staff layoffs may become necessary. The specter of layoffs or even the prospect of job reassignments will sooner or later spur some staff to oppose cutbacks they view as threats to their careers or job security. Management may be able to convince staff that delaying tactics in the long run will work to their disadvantage.

Anyone familiar with the unhappy circumstance that recently beset the printing industry may understand more clearly the consequences of prolonged, obstinate opposition to change. Compositors actively opposed managements that began to convert composition operations from hot-type machines to faster, cheaper, cold-type machines. The union objected; understandably, they were attempting to protect the jobs of members, but by doing so, both companies and union members were impacted by technology, and both companies and workers suffered as former markets were diminished. Companies went bankrupt, and the jobs of union members vanished.

Personnel problems related to technological displacement will persist only for a relatively short period of time. During this period, however, some library managers can anticipate heightened friction, tension, and occasional conflict between staff and management. One network planner has predicted, "The personnel turbulence which will result from more effective library networks and their impacts on the library will provide, perhaps, the greatest challenge to the network librarian that he has ever faced." 3

Circumstances will vary from library to library, but managers would be wise to look ahead and identify what options are available, how many staff are scheduled to retire, what is the normal turnover rate, who are the most trainable staff, and if the library or campus offers the necessary training courses. Library schools and professional associations along with other professionally oriented groups, such as the Continuing $\mathrm{Li}$ brary Education Network and Exchange (CLENE), will offer assistance, but the principal burden for retraining current staff will remain the responsibility of local libraries.

There is no shortage of work to be performed in libraries; there is only the need to decide which activities should receive highest priority. Staff are more versatile and flexible than most might suspect; catalogers can and are trained often to function as reference librarians, and reference librarians given adequate training can learn to provide services in a multi-institutional network environment. The crucial element is that management should begin to plan in order to anticipate problems rather than simply react to them as they occur.

\section{Resource Imbalance}

As libraries utilize the services offered through networks, imbalances in the current pattern of resource allocations among library activities will become more apparent. The current distribution of resources between activities associated with acquisition and cataloging and activities associated with providing user access to resources is one practical example. As user accessibility to bibliographic data via networks is improved, the demand for materials will grow because location information will be more quickly and easily accessible, but the movement of documents must still be accommodated by the already overburdened delivery systems. There is a strong possibility that libraries will be mandated to streamline their delivery systems.

The task of overhauling inter- and intrainstitution delivery systems may prove to be much more complicated than some might imagine. Systems must be designed to facilitate delivery within a campus community or between campus communities. All modes of transportation will have to be 
utilized, including the U.S. Postal Service, Greyhound Bus, UPS, delivery trucks, passenger buses, telefacsimile, and TWX. System planners must be able to discriminate between materials that are needed immediately and those that can be delivered in a week or two.

One of the lessons learned from the experiments with telefacsimile transmission systems conducted a few years ago was that a sizable percentage of users did not pick up materials immediately from the library upon notification of receipt. ${ }^{4}$ If a system of differentiated response could be designed, it would prove to be more effective in meeting user needs than is the case with current systems. ${ }^{5}$ Most likely the system would also prove more economical to operate.

More responsive document delivery systems will also be needed if librarians are to take seriously the objective of coordinated interinstitutional collection development. Coordinated collection development will also stimulate greater demands to move materials between campuses. Evidence of this phenomenon has already been reported by participants of the Research Libraries Group (RLG) program. Prior to RLG, 200 items were requested annually between the four members. In its first full year of operation, it was reported that RLG members had requested 5,423 items from project partners. ${ }^{6}$

Libraries proposing to participate in shared collection development agreements must eventually convince their local user constituencies that resource sharing will not degrade either local services or access to library resources. Students and particularly faculty who have come to expect books to be located close at hand may not view favorably a system that is predicated upon rapid delivery of books from a distant library. In order to overcome the objections and skepticisms that they now harbor, more dollar resources must surely be allocated to upgrade library delivery capabilities.

We are suggesting that the sequence of events just described will be set into motion, at first almost imperceptibly, as libraries assimilate network services as a regular component of their operations. The balance between bibliographic and physical accessibility represents only one of many operational balances that will be disturbed as a result of increased network utilization.

\section{SUMMARY}

The national bibliographic network, once available, will enhance a library's opportunity to serve its clientele. Planning, development, and implementation of networks represent a long-term, expensive commitment. Evidence of the movement toward a national network is clearly evident by organizations such as OCLC, NELINET, SOLINET, the Washington Library Network, and BALLOTS. These state and regional networks already provide valuable assistance to libraries by making cataloging data easier to obtain. New challenges and problems will confront library managers as current planning initiatives are transformed gradually into operational networks and as library organizations and functions begin to be impacted.

It would be prudent for library managers to identify as soon as possible those problems that can be anticipated and then to begin to formulate plans to deal with them. There seems to be no reason why careful planning cannot aid library managers to avoid the most serious pitfalls. Steps should be taken to insure that the benefits to be accrued from the national network will outweigh the problems of local transformation and accommodation.

\section{REFERENCES}

1. National Commission on Libraries and Information Science, Toward a National Program for Library and Information Services: Goals for Action (Washington, D.C.: The Commission, 1975).

2. Susan K. Martin, Library Networks; 1976-77 (White Plains, N.Y.: Knowledge Industry Publications, 1976).

3. Lawrence G. Livingston, "The Near Future of Library Networks in the United States," paper presented at the 1976 fall EDUCOM meeting in Boston, Massachusetts, p.7.

4. Nelson Associates, Inc., An Evaluation of the New York State Library's Pilot Program in the Facsimile Transmission of Library Materials (New York: Nelson Associates, 1968), p.42, 51.

5. University of California, Office of the Universitywide Planning, The University of California Library; A Plan for Development (Berkeley, Calif: Systemwide Administration, 1976), p. 49.

6. Research Libraries Group, Annual Report 1975-1976 (Branford, Conn.: Research Libraries Group, 1976), p.7. 